Article

\title{
An Untargeted Metabolomics Investigation of Jiulong Yak (Bos grunniens) Meat by ${ }^{1} \mathrm{H}-\mathrm{NMR}$
}

\author{
Chenglin Zhu ${ }^{1}\left(\mathbb{D}\right.$, Massimiliano Petracci ${ }^{1}\left(\mathbb{D}\right.$, Cheng Li $^{2}$, Enrico Fiore ${ }^{3} \mathbb{D}$ and Luca Laghi ${ }^{1, *}$ \\ 1 Department of Agro-Food Science and Technology, University of Bologna, 47521 Cesena, Italy; \\ chenglin.zhu2@unibo.it (C.Z.); m.petracci@unibo.it (M.P.) \\ 2 College of Food Science, Sichuan Agricultural University, Ya'an 625014, China; lichenglcp@163.com \\ 3 Department of Animal Medicine, Production and Health, University of Padova, \\ 35100 Legnaro (Padova), Italy; enrico.fiore@unipd.it \\ * Correspondence: 1.laghi@unibo.it; Tel.: +39-0547-338106
}

Received: 19 March 2020; Accepted: 26 March 2020; Published: 12 April 2020

\begin{abstract}
Yak represents the main meat source for Tibetan people. This work aimed to investigate the metabolome of raw meat from Jiulong yaks, focusing on specimens farmed and harvested locally through traditional procedures. Untargeted nuclear magnetic resonance spectroscopy $\left({ }^{1} \mathrm{H}-\mathrm{NMR}\right)$ was selected as the analytical platform. Samples from longissimus thoracis, trapezius, triceps brachii and biceps femoris muscles, with different prevalences of red and white fibers, were selected. Among the fifty-three metabolites quantified in each of them, carnitine, carnosine, creatine and taurine are known for their bioactive properties. Twelve molecules were found to be differently concentrated in relation to muscle type. Longissimus thoracis, compared to biceps femoris, had higher concentrations of carnosine and formate and lower concentrations of mannose, inosine, threonine, IMP, alanine, valine, isoleucine, tyrosine, phenylalanine and leucine. A metabolic pathway analysis suggested that the main pathways differing among the muscles were connected to the turnover of amino acids. These results contribute to a deeper understanding of yak raw meat metabolism and muscle type differences, which can be used as an initial reference for the meat industry to set up muscle-specific investigations. The possibility of simultaneously quantifying several bioactive compounds suggests that these investigations could revolve around meat's nutritional value.
\end{abstract}

Keywords: yak; meat; metabolome; proton nuclear magnetic resonance spectroscopy; pathway analysis

\section{Introduction}

Of the 14 million specimens of yak (Bos grunniens) bred in the world, 92\% are located in the Himalayan highlands region [1,2], where they represent the main, if not the only, source of meat for people living in conditions made extreme by altitude. This is because its high erythrocyte count [3] and its efficient energy and nitrogen utilization [4] make yak well adapted to the paucity of oxygen and energy sources [5]. Its peculiar enzyme activity and gene expression profile [6] have positive consequences also on the meat quality characteristics, specifically on tenderness, juiciness and leanness [7]. These appreciable properties seem to be mainly linked to three muscles' physiological features. Firstly, yak meat shows, throughout all the maturation steps, an intense protease activity [8] causing a pronounced myofibrillar denaturation and fragmentation in correspondence to the Z-line [9]. In addition, the final $\mathrm{pH}$ of yak meat is peculiarly distant from the isoelectric point [10]. Moreover, yak shows a lower intramuscular fat content in comparison with beef. 
In the last decade, a new insight into the links between physiological properties of bovine meat and its quality characteristics has been offered by the advent of "omics" approaches. One example is offered by meta-proteomics, which was successfully applied to investigate the biomarkers of beef tenderness [11]. In this context, metabolomics seems particularly promising, because the cohort of meat's low weight molecules, the so called metabolome, is considered as the most complete representation of its phenotype [12]. Indeed, up to now several aspects of meat quality have been explored from a metabolomics perspective [13], comprised of the effects of treatments such as aging or packaging conditions [14].

Among the platforms granting the needed high throughput, ${ }^{1} \mathrm{H}-\mathrm{NMR}$ spectroscopy has been widely used for investigations on cattle meat, because of its high reproducibility and the minimal sample preparation required. For example, Castejón et al. and Graham et al. $[15,16]$ were able to evidence the metabolome profile evolution that occurs in beef tenderloins during its conservation. Ritota et al. [17] demonstrated the feasibility of employing meat's metabolome to discriminate cattle breeds. Geographical origin [18,19] and meat's treatments [20] were also studied through a metabolomics approach.

Despite the numerous applications of metabolomics in cattle meat, meat from the other bovine species has been rarely described. Examples can be traced only in the works by Ritota et al. [17], who observed buffaloes in relation to bovines, and in the work by Luo et al., who quantified 17 amino acids in the meat of domestic and semi-wild yaks [21]. Moreover, metabolomic investigations have generally observed meat from any bovine species as a matrix with homogenic characteristics, without considering the peculiarities of the different muscles. This also includes the most basic peculiarities, such as the prevalence of white and red fibers.

In the desire to set the basis for the development of metabolomics investigations of yak's meat, with the present paper we would like to outline its metabolome, as can be observed by ${ }^{1} \mathrm{H}-\mathrm{NMR}$. For this purpose we focus on one of its sub-species, Jiulong, representing approximately $30 \%$ of all yaks [22] bred at present in China. Meat metabolome is the result of the genetics of the animal, together with the breeding conditions and with the slaughtering procedures. This is particularly true for yak, for which tradition can still play a key role in breeding and processing procedures. To obtain a realistic picture of Jiulong yak meat, we collected samples from a facility still conducted traditionally, located in the area where these animals are mainly bred. To give a comprehensive metabolomic picture of Jiulong yak's meat, we consider four muscles known to show a marked difference in the ratio between red and white fibers.

\section{Materials and Methods}

\subsection{Sampling}

We collected raw meat samples from male Jiulong yaks ( $36 \pm 2$ months of age) in a public abattoir (without modern slaughtering equipment) located in the pastoral area of Litang County (altitude $4000 \mathrm{~m}$ ), Sichuan, China, at the end of August. Yaks are generally slaughtered at this time of the year at three years of age, because they reach the highest weight and have optimal health conditions.

The yaks had been transported to the abattoir and held in lairage for $24 \mathrm{~h}$ with water supplementation until $3 \mathrm{~h}$ before slaughtering. The yaks had been sacrificed following the local traditional manual procedures [22]. As described by Graham et al. [16], forty-five minutes post-mortem, one side of each carcass had been hung by the Achilles tendon and the other side had been hung using the pelvic suspension.

Two hours later, from 10 consecutively slaughtered animals we collected 7 samples of triceps brachii (TB), 5 samples of biceps femoris (BF), 5 samples of longissimus thoracis (LT) and 3 samples of trapezius (TP). The samples, weighing approximately $10 \mathrm{~g}$, were immediately placed in bags at $4{ }^{\circ} \mathrm{C}$. The discrepancies in the number of samples are linked to practical reasons during the slaughtering procedures. In detail, the TP muscle was generally removed together with the head, so that only three samples were collected. 
In the case of the other muscles, some samples could not be collected due to the impossibility to slow down the slaughtering procedures. This resulted in a total of 20 samples for metabolomics investigation. We transported all samples in dry ice and stored them prior to analysis at $-80^{\circ} \mathrm{C}$.

\subsection{Metabolome Analysis}

To create yak meat samples suitable for ${ }^{1} \mathrm{H}-\mathrm{NMR}$ analysis, we added two grams of meat to $12 \mathrm{~mL}$ of distilled water, and then we homogenized the mixture for $5 \mathrm{~min}$ by means of a high-speed disperser (IKA, Staufen im Breisgau, Germany). Then, we centrifuged $1 \mathrm{~mL}$ of the mixed sample at 18,630 $\mathrm{g}$ and $4{ }^{\circ} \mathrm{C}$ for $15 \mathrm{~min}$. To get rid of the fat fraction, we transferred $0.7 \mathrm{~mL}$ of the supernatant fraction to a new Eppendorf tube containing $0.8 \mathrm{~mL}$ chloroform, we vortex mixed for $3 \mathrm{~min}$ and we centrifuged again at the above conditions. We added the supernatants $(0.5 \mathrm{~mL})$ to $0.2 \mathrm{~mL}$ of a $\mathrm{D}_{2} \mathrm{O}$ solution, buffered at $\mathrm{pH}$ $7.00 \pm 0.02$ with a $1 \mathrm{M}$ phosphate buffer, containing 3-(trimethylsilyl)-propionic-2,2,3,3- $\mathrm{d}_{4}$ acid sodium salt (TSP) $10 \mathrm{mM}$, used as NMR chemical-shift reference, and $\mathrm{NaN}_{3} 2 \mathrm{mM}$, used to avoid microbial proliferation. We finally centrifuged each sample at the above conditions.

We acquired ${ }^{1} \mathrm{H}-\mathrm{NMR}$ spectra at $298 \mathrm{~K}$ by means of an AVANCE III spectrometer (Bruker, Milan, Italy) operating at a frequency of $600.13 \mathrm{MHz}$. According to Zhu et al. [23], we suppressed the signals from broad resonances originating from large molecules with a CPMG-filter composed by 400 echoes with a $180^{\circ}$ pulse of $24 \mu \mathrm{s}$ and a $\tau$ of $400 \mu \mathrm{s}$, for a total filter of $330 \mathrm{~ms}$. We suppressed the HOD residual signal through presaturation. We achieved this goal by employing the cpmgpr1d sequence, part of the standard pulse sequence library. We acquired each spectrum by summing up 256 transients, using $32 \mathrm{~K}$ data points over a $7184 \mathrm{~Hz}$ spectral window, with an acquisition time of $2.28 \mathrm{~s}$. We adjusted the spectra baseline by detecting each peak according to the "rolling ball" strategy [24], implemented in the baseline R package [25]. We considered the differences in water content among samples by probabilistic quotient normalization (PQN) [26], applied to the entire array of spectra. We performed signals' assignment by comparing their chemical shift and multiplicity with the Chenomx software library (Chenomx Inc., Edmonton, Canada, ver. 8.3), as shown in Figures S1-S12. We performed molecules' quantification by taking advantage of TSP as a reliable internal standard. We integrated the signals for each molecule by means of rectangular integration. A graphic representation of the workflow for meat samples preparation and ${ }^{1} \mathrm{H}-\mathrm{NMR}$ spectra processing is shown in Figure S13.

\subsection{Statistical Analysis}

For statistical analysis we employed R computational language (ver. 3.6.1.) [27]. We transformed variables that were not-normally distributed according to Box and Cox [28]. Following Abadie et al. [29], we looked for molecules, whose concentration varied among muscle types, with ANOVA, followed by Tukey HSD post hoc test $(p<0.05)$. Due to the low number of samples in TP group, we investigated the differences between LT and TP groups focusing on fold change, as suggested by Wang et al. [30].

In order to obtain an overall of the trends underlying the metabolome of the samples, we calculated robust principal component analysis (rPCA) models [31] for the molecules accepted by the above described univariate analysis. For each rPCA model, we calculated the scoreplot, the projection of the samples in the PC space, tailored to highlight the structure of the data. In addition, we calculated the Pearson correlation to find out the relations between the concentration of each molecule and the components of the model.

We highlighted the most relevant metabolic pathways differing among the muscle types by pathway analysis, performed by means of MetaboAnalyst 4.0 [32]. For this purpose, we considered only the molecules whose concentrations were significantly different in the univariate analysis. 


\section{Results}

\section{1. ${ }^{1}$ H-NMR Spectra of Yak Raw Meat}

The ${ }^{1} \mathrm{H}-\mathrm{NMR}$ spectra of each yak muscle type are reported in Figure 1, while molecules' concentrations are reported in Table S1. A total of 53 molecules were identified and quantified, pertaining mainly to the chemical groups of amino acids, peptides and analogues, carbohydrates and derivates, organic acids and derivates, nucleosides, nucleotides and analogues. Among all the molecules characterized and quantified by ${ }^{1} \mathrm{H}-\mathrm{NMR}$, carnitine, carnosine, taurine and creatine, are known as bioactive compounds. A bioactive compound is an extra nutritional constituent of food that can have a positive impact on body functions and may ultimately promote health [33].
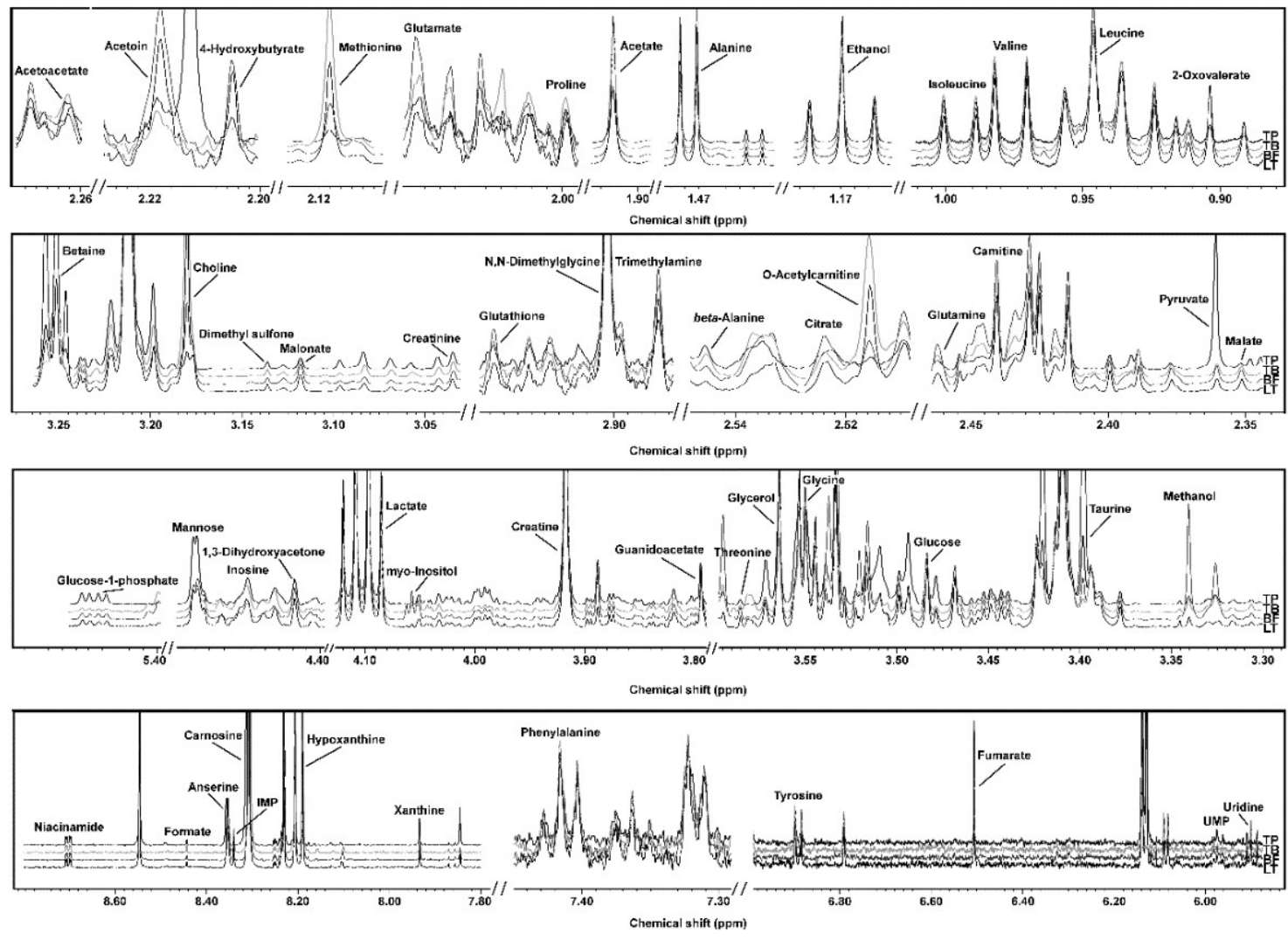

Figure 1. ${ }^{1} \mathrm{H}-\mathrm{NMR}$ spectra from trapezius (TP), triceps brachii (TB), biceps femoris (BF) and longissimus thoracis (LT), representative of all the registered spectra. The name of each molecule appears over the signal used for its quantification. To ease the reader's visual inspection, for each portion a spectrum with a convenient signal-to-noise ratio has been selected. The entire spectra and molecules identification is shown in Figures S2-S13.

\subsection{Comparison among TB, BF and LT Muscles}

Twelve of the quantified molecules were significantly different among TB, BF and LT muscles, namely carnosine, formate, mannose, inosine, threonine, IMP, alanine, valine, isoleucine, tyrosine, phenylalanine and leucine (Table 1). 
Table 1. Molecules in yak raw meat with a concentration (mmol/g, median (IQR)) significantly different among muscle types.

\begin{tabular}{ccccc}
\hline & Triceps brachii $\mathbf{( T B )}$ & Biceps femoris $(\mathrm{BF})$ & Longissimus thoracis $(\mathrm{LT})$ & $p$ \\
\hline Alanine & $4.76 \times 10^{-3}\left(1.33 \times 10^{-3}\right)^{a}{ }^{a}$ & $5.31 \times 10^{-3}\left(4.77 \times 10^{-4}\right)^{a}$ & $3.14 \times 10^{-3}\left(9.50 \times 10^{-4}\right)^{b}$ & 0.003 \\
Carnosine & $1.23 \times 10^{-2}\left(1.65 \times 10^{-3}\right)^{b}$ & $1.60 \times 10^{-2}\left(8.17 \times 10^{-3}\right)^{b}$ & $2.09 \times 10^{-2}\left(1.84 \times 10^{-3}\right)^{a}$ & 0.017 \\
Isoleucine & $1.81 \times 10^{-4}\left(3.39 \times 10^{-5}\right)^{a b}$ & $2.33 \times 10^{-4}\left(6.07 \times 10^{-5}\right)^{a}$ & $1.69 \times 10^{-4}\left(4.61 \times 10^{-5}\right)^{b}$ & 0.012 \\
Leucine & $3.54 \times 10^{-4}\left(7.22 \times 10^{-5}\right)^{a b}$ & $4.70 \times 10^{-4}\left(9.67 \times 10^{-5}\right)^{a}$ & $3.06 \times 10^{-4}\left(9.42 \times 10^{-5}\right)^{b}$ & 0.007 \\
Phenylalanine & $2.48 \times 10^{-4}\left(7.34 \times 10^{-5}\right)^{a b}$ & $3.37 \times 10^{-4}\left(7.77 \times 10^{-5}\right)^{a}$ & $2.39 \times 10^{-4}\left(4.65 \times 10^{-5}\right)^{b}$ & 0.013 \\
Threonine & $3.25 \times 10^{-4}\left(1.88 \times 10^{-4}\right)^{a}$ & $4.27 \times 10^{-4}\left(1.55 \times 10^{-4}\right)^{a}$ & $2.49 \times 10^{-4}\left(4.85 \times 10^{-5}\right)^{b}$ & 0.008 \\
Tyrosine & $1.86 \times 10^{-4}\left(2.99 \times 10^{-5}\right)^{a b}$ & $2.02 \times 10^{-4}\left(5.03 \times 10^{-5}\right)^{a}$ & $1.60 \times 10^{-4}\left(3.46 \times 10^{-5}\right)^{b}$ & 0.011 \\
Valine & $3.28 \times 10^{-4}\left(4.58 \times 10^{-5}\right)^{a b}$ & $3.99 \times 10^{-4}\left(7.97 \times 10^{-5}\right)^{a}$ & $3.03 \times 10^{-4}\left(7.23 \times 10^{-5}\right)^{b}$ & 0.019 \\
Mannose & $2.73 \times 10^{-4}\left(4.26 \times 10^{-5}\right)^{a b}$ & $3.11 \times 10^{-4}\left(9.82 \times 10^{-5}\right)^{a}$ & $2.35 \times 10^{-4}\left(3.08 \times 10^{-5}\right)^{b}$ & 0.039 \\
Formate & $7.43 \times 10^{-5}\left(7.88 \times 10^{-6}\right)^{a b}$ & $6.94 \times 10^{-5}\left(1.85 \times 10^{-5}\right)^{b}$ & $8.34 \times 10^{-5}\left(5.95 \times 10^{-6}\right)^{a}$ & 0.012 \\
IMP & $1.39 \times 10^{-4}\left(1.74 \times 10^{-4}\right)^{a b}$ & $4.30 \times 10^{-4}\left(2.29 \times 10^{-4}\right)^{a}$ & $1.20 \times 10^{-4}\left(3.44 \times 10^{-5}\right)^{b}$ & 0.031 \\
Inosine & $1.73 \times 10^{-4}\left(1.35 \times 10^{-4}\right)^{a b}$ & $3.81 \times 10^{-4}\left(1.89 \times 10^{-4}\right)^{a}$ & $1.76 \times 10^{-4}\left(4.33 \times 10^{-5}\right)^{b}$ & 0.021 \\
\hline
\end{tabular}

An rPCA model was built of these concentrations to obtain an overview of their trends, as shown in Figure 2.

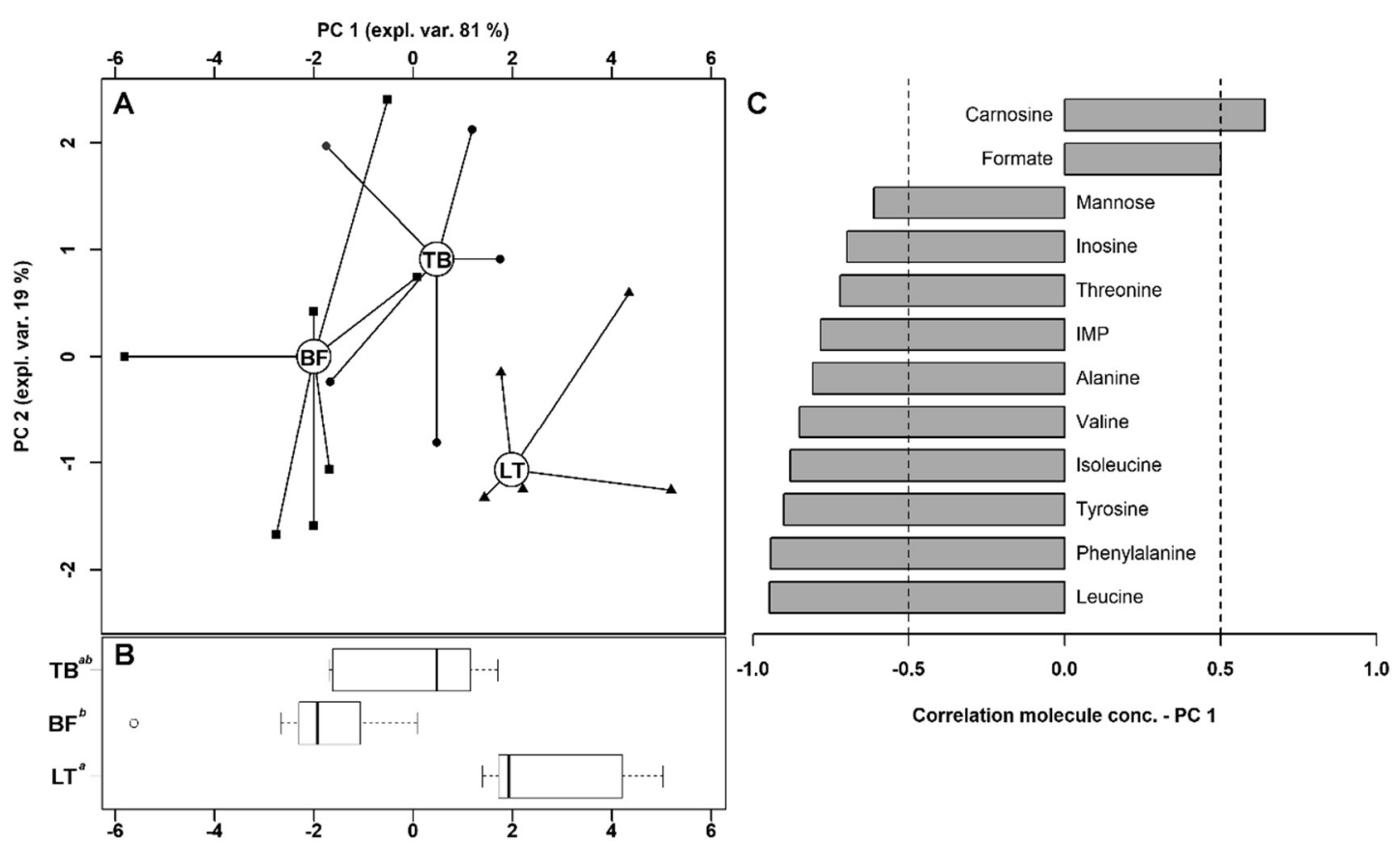

Figure 2. rPCA model built of these concentration of the molecules showing statistically significant differences among different groups. In the scoreplot (A), samples from the three groups are represented with triangles (LT), circles (TB) and squares (BF). The wide, empty circles represent the median of each samples' group. In the boxplot (B), the position of the samples along PC 1 is summarized. Different superscript letters identify significantly different groups $(p<0.05)$. The loading plot $(\mathbf{C})$ reports the correlation between the concentration of each substance and its importance over PC 1.

The PC 1 of its scoreplot (Figure 2A), representing as much as the $81 \%$ of the entire samples' variability so described, summarizes the differences between the samples collected from different muscles. In detail, LT muscle was found to be characterized by lower concentrations of mannose, inosine, threonine, IMP, alanine, valine, isoleucine, tyrosine, phenylalanine and leucine and higher concentrations of carnosine and formate. 
The 12 molecules were used as a basis for a pathway enrichment analysis, to identify the most relevant pathways differentiating the muscles. Three pathways were highlighted: namely the valine, leucine and isoleucine biosynthesis pathway; the phenylalanine, tyrosine and tryptophan biosynthesis pathway and phenylalanine metabolism pathway.

\subsection{Comparison between LT and TP Muscles}

The last column of Table S1 lists the fold change differences of TP in comparison to LT samples. The concentrations of taurine and acetoin were considerably higher in LT samples, while the concentrations of glutamine, methionine, hypoxanthine, IMP, inosine, myo-inositol, choline, methanol and o-acetylcarnitine showed an opposite trend. In particular, the concentration of myo-inositol was 10 times higher in TP compared to LT samples.

To relate the metabolome of TP muscle with those of the other muscles, we treated the TP samples as an independent test set by projecting them over the rPCA described in Figure 2, as described by Figure 3. This choice evidenced that PC 2 was mainly influenced by muscle location along the yak, with the samples obtained from the legs characterized by positive PC 2 scores and the samples obtained from the longissimus thoracis and trapezius characterized by negative PC 2 scores. PC 1 scores appeared mainly as associated to the ratio between red and white fibers, with muscles with a prevalence of white fibers characterized by positive scores.

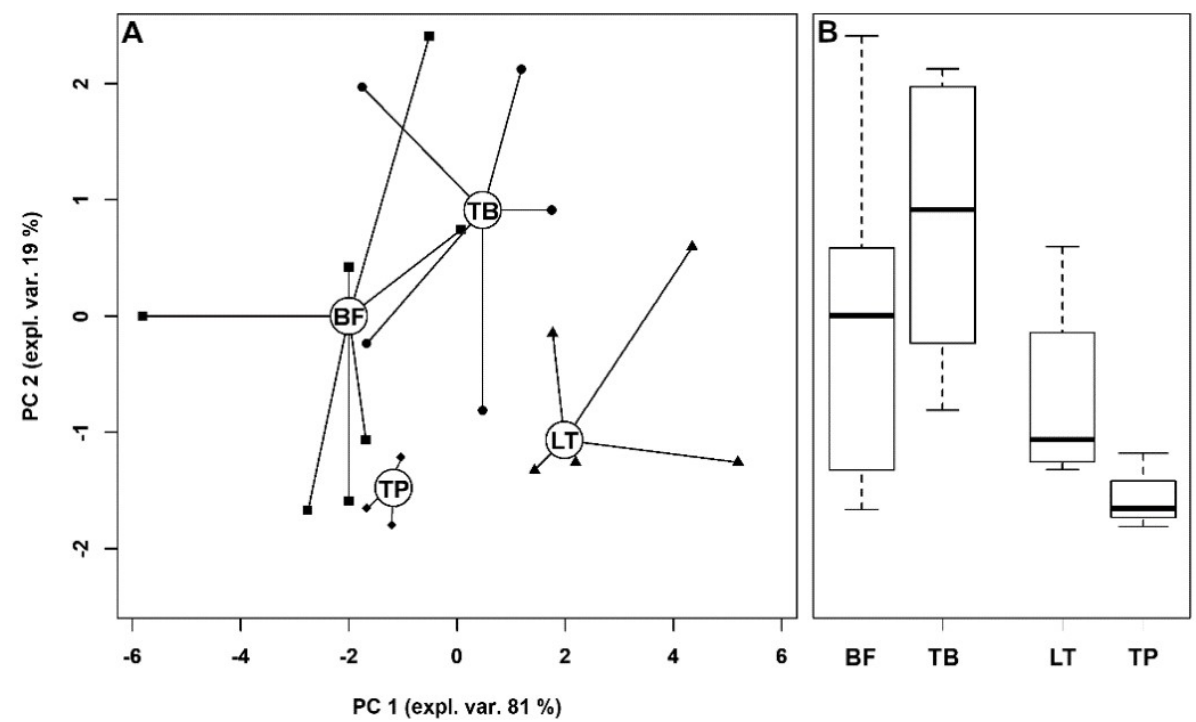

Figure 3. (A) Scoreplot of the rPCA model described in Figure 2, where TP samples have been projected. The wide, empty circles represent the median of the samples from the various types of muscles.

(B) Boxplots summarizing the samples' positions along PC 2.

\section{Discussion}

This is the first study that characterizes, through an untargeted approach by ${ }^{1} \mathrm{H}-\mathrm{NMR}$, raw yak meat metabolome. A total of 53 metabolites were unambiguously identified, a twofold number compared to previous studies on cattle beef investigated relying on the same analytical platform $[13,16]$. As a primer in the field, we devoted an intense effort to set up each aspect of the procedures for sample preparation and data mining so as to ease their reproduction. One of the main problems hindering ${ }^{1} \mathrm{H}-\mathrm{NMR}$ data reproduction is signals' misalignment, caused by $\mathrm{pH}$ or ionic strength differences from sample to sample [12]. Figure 1 allows one to visually appreciate that the experimental conditions selected led to ${ }^{1} \mathrm{H}-\mathrm{NMR}$ spectra conveniently aligned, not requiring the application of algorithms for signal-by-signals shifting, differently from previous works [34]. In addition, Figures S2-S13 assist the reader in the signals' assignment and quantification step, thus allowing the reproduction and double 
check of our assignments. These details are in line with the recommendations outlined by the EU Initiative "coordination of standards in metabolomics" (COSMOS) [35].

LT muscle is characterized by a peculiarly high number of white, fast-twitching glycolytic fibers. However, TP muscle harbors a higher number of slow-twitching oxidative fibers, while TB and BF can be considered as intermediate between the two [36-38]. Carnosine content is known to reflect the ratio between glycolytic and oxidative fibers. This molecule is therefore higher in white muscles, where it grants a high buffering capacity, thus compensating for the lactic acid accumulation connected to the anaerobic metabolism [39]. The concentration of this histidine-containing dipeptide we measured was coherent with such findings, being in LT muscle $42 \%$ higher than TB and $24 \%$ higher than BF. The comparison of the trends between the samples from TP and LT muscle seems a further confirmation, with the former characterized by higher concentration than the latter, in agreement with the observations in beef by Aristoy et al. [40]. From this point of view, some discrepancies in the literature must be evidenced. Mora et al. [41], for example, found similar carnosine concentrations in pigs in LT and BF, likely in connection with peculiarities connected to species and environment. Environment is expected to play a key role in the physiological differences between yak and other species or cattle breeds, with yak perfectly adapted to graze on steep slopes and in harsh environments.

Univariate analysis showed that the muscle type had a profound effect on the amino acids overall profile, with significant effects on the concentration of 7 amino acids of the 14 measured. Moreover, enrichment analysis showed that all the most altered pathways were related to amino acids metabolism. A similarly profound effect of muscle type on amino acids profile has also been observed for cattle [42], with consequences on important characteristics for meat quality like oxidative stability.

The fact that each of the seven amino acids showed a negative correlation with PC 1 scores suggests that the main reason for such trend is linked to the use of the muscles, more intense for legs and neck. The concentration of each of them was statistically different between BF and LT. Generally, TB showed intermediate values. An exception was represented by alanine, differently concentrated between TB and LT. Alanine is a non-essential amino acid, highly concentrated in muscles, where it serves as one of the major energy sources [43]. Goldstein et al. [44] noted that the release of alanine by muscle is a metabolic consequence of both the initial transamination reaction and its conversion into pyruvate via the normal oxidation pathway for the amino acids. In vivo, alanine can be produced from the breakdown of carnosine [45], which could explain the inverse relationship between the concentration of alanine and carnosine we noticed in the present investigation.

IMP pertains to the molecules derived from purines, often produced by ATP hydrolysis during the aging process of beef samples [46]. Dannert et al. [47] found that the concentration of IMP is not significantly different among the LT, BF and semimembranosus muscles of pork carcasses sampled $48 \mathrm{~h}$ post-mortem. However, we found in yak that the concentration of IMP was significantly higher in $\mathrm{BF}$ than in LT. This discrepancy suggests that the degradation phenomena occurring during muscles transformation into meat are likely to be, in yak, strongly muscle specific [48].

In spite of potential applications of the information obtained in the present work as a base for the valorization of yak's meat, it is important to notice that among all the molecules characterized, four, namely carnitine, carnosine, taurine and creatine, are appreciated for their bioactive properties.

Carnitine is not an essential nutrient for humans, but $75 \%$ of it needs to be taken from food, mainly from meat. The major function of carnitine is to transport long chain fatty acids across inner mitochondrial membranes where the fatty acids are converted into biological energy by alpha-oxidation [49]. Similarly to carnitine, taurine is also a conditionally essential compound, because it cannot be synthesized in sufficient quantities by the human body. This substance has multiple functions and plays a significant role in many physiological processes, such as osmoregulation, immunomodulation and bile salt formation [50]. Creatine plays an important role in energy provision in muscle contraction, and its supplementation can increase the performance of muscles [51]. 


\section{Conclusions}

This is the first work devoted to the characterization of the metabolome of raw yak meat by means of untargeted ${ }^{1} \mathrm{H}-\mathrm{NMR}$. As a primer in this context, we desired to analyze samples from the region where these animals are mainly bred and harvested through traditional procedures. This choice limited the number of samples analyzed, but a number of metabolites greater than previously reported for beef were still characterized. The metabolome profile which emerged appeared as strongly sensitive to the differences among muscles. This was particularly true for amino acids and degradation related molecules, suggesting therefore that the protocol described here could serve as a base for muscle specific studies of the transformations occurring in meat upon aging.

The present experiment showed that several bioactive molecules could be simultaneously and readily quantified by ${ }^{1} \mathrm{H}-\mathrm{NMR}$, despite their chemical heterogeneity. The reference values listed in the present work set the basis for observations about the effects of processing practices on the nutritional value of meat, or for works aiming to valorize meat from this remarkable animal.

Supplementary Materials: The following are available online at http://www.mdpi.com/2304-8158/9/4/481/s1, Figures S1: Graphic design of the workflow for meat samples preparation and ${ }^{1} \mathrm{H}-\mathrm{NMR}$ spectra processing, Figures S2-S13: Above panel - portions of the spectra, superimposed in white-washed mode. The black and red dashed lines show the portions of the spectra employed for the quantification of each molecule. Below one representative spectrum (black line) superimposed to the signals simulated by software Chenomx (red line) for each of the molecules listed; Table S1: Concentrations (mmol/g, median (IQR)) of molecules quantified by ${ }^{1} \mathrm{H}-\mathrm{NMR}$.

Author Contributions: Conceptualization, C.Z. and L.L.; methodology, C.Z. and L.L.; formal analysis, C.Z. and L.L.; investigation, C.Z.; writing—original draft preparation, C.Z. and L.L.; writing-review and editing, C.Z., M.P., C.L., E.F. and L.L.; supervision, L.L. All authors have read and agreed to the published version of the manuscript.

Funding: This research received no external funding.

Acknowledgments: Chenglin Zhu gratefully acknowledges financial support from the Chinese Scholarship Council (grant no. 201606910076). Enrico Fiore gratefully acknowledges financial support from the University of Padova (grant no. BIRD195883).

Conflicts of Interest: The authors declare no conflict of interest.

\section{References}

1. Zi, X.D.; Zhong, G.H.; Wen, Y.L.; Zhong, J.C.; Liu, C.L.; Ni, Y.A.; Yezi, Y.H.; Ashi, M.G. Growth performance, carcass composition and meat quality of Jiulong-yak (Bos grunniens). Asian-Australas. J. Anim. Sci. 2004, 17, 410-414. [CrossRef]

2. Zhang, Y.; Liu, J.; Zhang, D.; Hasegawa, M.; Liu, W.; Zhang, J.; Ma, T.; Cao, C.; Lenstra, J.A.; Zang, X.; et al. The yak genome and adaptation to life at high altitude. Nat. Genet. 2012, 44, 946-949.

3. Zhang, L.; Wu, J.; Wang, X.; Liu, B.; Ma, B. Isolation of metallothionein genes and in silico structural characterization of their proteins Using molecular modeling from Yak (Bos grunniens). Biochem. Genet. 2012, 50, 585-599. [CrossRef]

4. Shang, Z.; Liang, J.B.; Long, R.; Wang, H.; Ding, L.; Guo, X. Comparison of Nitrogen Metabolism in Yak (Bos grunniens) and Indigenous Cattle (Bos taurus) on the Qinghai-Tibetan Plateau. Asian-Australas. J. Anim. Sci. 2011, 24, 766-773.

5. Zhang, Q.; Gong, J.; Wang, X.; Wu, X.; Li, Y.; Ma, Y.; Zhang, Y.; Zhao, X. Molecular cloning, bioinformatics analysis and expression of insulin-like growth factor 2 from tianzhu white yak, Bos grunniens. Int. J. Mol. Sci. 2014, 15, 504-524. [CrossRef] [PubMed]

6. Lin, Y.Q.; Wang, G.S.; Feng, J.; Huang, J.Q.; Xu, Y.O.; Jin, S.Y.; Li, Y.P.; Jiang, Z.R.; Zheng, Y.C. Comparison of enzyme activities and gene expression profiling between yak and bovine skeletal muscles. Livest. Sci. 2011, 135, 93-97. [CrossRef]

7. Zhang, L.; Sun, B.; Yu, Q.; Ji, Q.; Xie, P.; Li, H.; Wang, L.; Zhou, Y.; Li, Y.; Huang, C.; et al. The breed and sex effect on the carcass size performance and meat quality of yak in different muscles. Korean J. Food Sci. Anim. Resour. 2016, 36, 223-229. [CrossRef] 
8. Shi, X.X.; Yu, Q.L.; Han, L.; Tian, J.C.H.; Zhang, L.; Zhang, Y.B.; Guo, Z.H.B. Changes in meat quality characteristics and calpains activities in Gannan Yak (Bos grunniens) meat during post mortem ageing. J. Anim. Vet. Adv. 2013, 12, 363-368.

9. Rajagopal, K.; Oommen, G.T. Myofibril Fragmentation Index as an Immediate Postmortem Predictor of Buffalo Meat Tenderness. J. Food Process. Preserv. 2015, 39, 1166-1171. [CrossRef]

10. Jia, J.; Zhang, Q.; Chen, Q.; Zhang, H.; Lin, F.; Zhao, J. Differential expression of proteins in Datong Yak and Chaidamu yellow cattle longissimus lumborum muscles and relation to meat water holding capacity. Kafkas Univ. Vet. Fak. Derg. 2018, 24, 691-700.

11. Picard, B.; Gagaoua, M. Meta-proteomics for the discovery of protein biomarkers of beef tenderness: An overview of integrated studies. Food Res. Int. 2020, 127, 108739. [CrossRef] [PubMed]

12. Laghi, L.; Picone, G.; Capozzi, F. Nuclear magnetic resonance for foodomics beyond food analysis. TrAC Trends Anal. Chem. 2014, 59, 93-102. [CrossRef]

13. Kodani, Y.; Miyakawa, T.; Komatsu, T.; Tanokura, M. NMR-based metabolomics for simultaneously evaluating multiple determinants of primary beef quality in Japanese Black cattle. Sci. Rep. 2017, 7, 1-13. [CrossRef] [PubMed]

14. Ercolini, D.; Ferrocino, I.; Nasi, A.; Ndagijimana, M.; Vernocchi, P.; La Storia, A.; Laghi, L.; Mauriello, G.; Guerzoni, M.E.; Villani, F. Monitoring of microbial metabolites and bacterial diversity in beef stored under different packaging londitions. Appl. Environ. Microbiol. 2011, 77, 7372-7381. [CrossRef] [PubMed]

15. Castejón, D.; García-Segura, J.M.; Escudero, R.; Herrera, A.; Cambero, M.I. Metabolomics of meat exudate: Its potential to evaluate beef meat conservation and aging. Anal. Chim. Acta 2015, 901, 1-11. [CrossRef]

16. Graham, S.F.; Kennedy, T.; Chevallier, O.; Gordon, A.; Farmer, L.; Elliott, C.; Moss, B. The application of NMR to study changes in polar metabolite concentrations in beef longissimus dorsi stored for different periods post mortem. Metabolomics 2010, 6, 395-404. [CrossRef]

17. Ritota, M.; Casciani, L.; Failla, S.; Valentini, M. HRMAS-NMR spectroscopy and multivariate analysis meat characterisation. Meat Sci. 2012, 92, 754-761. [CrossRef]

18. Jung, Y.; Lee, J.; Kwon, J.; Lee, K.S.; Ryu, D.H.; Hwang, G.S. Discrimination of the geographical origin of beef by 1 H NMR-based metabolomics. J. Agric. Food Chem. 2010, 58, 10458-10466. [CrossRef]

19. Shintu, L.; Caldarelli, S.; Franke, B.M. Pre-selection of potential molecular markers for the geographic origin of dried beef by HR-MAS NMR spectroscopy. Meat Sci. 2007, 76, 700-707. [CrossRef]

20. Zanardi, E.; Caligiani, A.; Palla, L.; Mariani, M.; Ghidini, S.; Di Ciccio, P.A.; Palla, G.; Ianieri, A. Metabolic profiling by $1 \mathrm{H}$ NMR of ground beef irradiated at different irradiation doses. Meat Sci. 2015, 103, 83-89. [CrossRef]

21. Luo, X.L.; Tong, Z.B.; Wei, Y.P.; Zhao, X.Q. Meat characteristics of Qinghai yak and semi-wild yak. Anim. Sci. J. 2006, 77, 230-234. [CrossRef]

22. Wiener, G.; Han, J.; Long, R. The Yak, 2nd ed.; FAO Regional Office for Asia and the Pacific, Ed.; FAO Regional Office for Asia and the Pacific: Bangkok, Thailand, 2003; ISBN 92-5-104965-3.

23. Zhu, C.; Faillace, V.; Laus, F.; Bazzano, M.; Laghi, L. Characterization of trotter horses urine metabolome by means of proton nuclear magnetic resonance spectroscopy. Metabolomics 2018, 14, 106. [CrossRef] [PubMed]

24. Kneen, M.A.; Annegarn, H.J. Algorithm for fitting XRF, SEM and PIXE X-ray spectra backgrounds. Nucl. Instrum. Methods Phys. Res. Sect. B Beam Interact. Mater. At. 1996, 109-110, 209-213. [CrossRef]

25. Liland, K.H.; Almøy, T.; Mevik, B.H. Optimal choice of baseline correction for multivariate calibration of spectra. Appl. Spectrosc. 2010, 64, 1007-1016. [CrossRef]

26. Dieterle, F.; Ross, A.; Schlotterbeck, G.; Senn, H. Probabilistic quotient normalization as robust method to account for dilution of complex biological mixtures. Application in1H NMR metabonomics. Anal. Chem. 2006, 78, 4281-4290. [CrossRef]

27. R Development Core Team. R: A Language and Environment for Statistical Computing. Available online: https://www.gbif.org/tool/81287/r-a-language-and-environment-for-statistical-computing (accessed on 15 March 2020).

28. Box, G.E.P.; Cox, D.R. An Analysis of Transformations. J. R. Stat. Soc. Ser. B 2018, 26, 211-243. [CrossRef]

29. Abadie, V.; Kim, S.M.; Lejeune, T.; Palanski, B.A.; Ernest, J.D.; Tastet, O.; Voisine, J.; Discepolo, V.; Marietta, E.V.; Hawash, M.B.F.; et al. IL-15, gluten and HLA-DQ8 drive tissue destruction in coeliac disease. Nature 2020, 578, 600-604. [CrossRef]

30. Wang, H.; Zhong, H.; Hou, R.; Ayala, J.; Liu, G.; Yuan, S.; Yan, Z.; Zhang, W.; Liu, Y.; Cai, K.; et al. A Diet Diverse in Bamboo Parts is Important for Giant Panda (Ailuropoda melanoleuca) Metabolism and Health. Sci. Rep. 2017, 7, 1-13. [CrossRef] 
31. Hubert, M.; Rousseeuw, P.J.; Vanden Branden, K. ROBPCA: A new approach to robust principal component analysis. Technometrics 2005, 47, 64-79. [CrossRef]

32. Li, C.; Soufan, O.; Chong, J.; Xia, J.; Bourque, G.; Li, S.; Caraus, I.; Wishart, D.S. MetaboAnalyst 4.0: Towards more transparent and integrative metabolomics analysis. Nucleic Acids Res. 2018, 46, W486-W494.

33. Marcolini, E.; Babini, E.; Bordoni, A.; Di Nunzio, M.; Laghi, L.; Maczó, A.; Picone, G.; Szerdahelyi, E.; Valli, V.; Capozzi, F. Bioaccessibility of the Bioactive Peptide Carnosine during in Vitro Digestion of Cured Beef Meat. J. Agric. Food Chem. 2015, 63, 4973-4978. [CrossRef] [PubMed]

34. Bordoni, A.; Picone, G.; Babini, E.; Vignali, M.; Danesi, F.; Valli, V.; Di Nunzio, M.; Laghi, L.; Capozzi, F. NMR comparison of in vitro digestion of Parmigiano Reggiano cheese aged 15 and 30 months. Magn. Reson. Chem. 2011, 49, S61-S70. [CrossRef] [PubMed]

35. Salek, R.M.; Neumann, S.; Schober, D.; Hummel, J.; Billiau, K.; Kopka, J.; Correa, E.; Reijmers, T.; Rosato, A.; Tenori, L.; et al. COordination of Standards in MetabOlomicS (COSMOS): Facilitating integrated metabolomics data access. Metabolomics 2015, 11, 1587-1597. [CrossRef] [PubMed]

36. Lawrie, R.A.; Pomeroy, R.W.; Williams, D.R. Studies in the muscles of meat animals. IV. Comparative composition of muscles from 'doppelender' and normal sibling heifers. J. Agric. Sci. 1964, 62, 89-92. [CrossRef]

37. Rao, M.V.; Gault, N.F.S. The influence of fibre-type composition and associated biochemical characteristics on the acid buffering capacities of several beef muscles. Meat Sci. 1989, 26, 5-18. [CrossRef]

38. Flores, M.; Alasnier, C.; Aristoy, M.C.; Navarro, J.L.; Gandemer, G.; Toldrá, F. Activity of aminopeptidase and lipolytic enzymes in five skeletal muscles with various oxidative patterns. J. Sci. Food Agric. 1996, 70, 127-130. [CrossRef]

39. Suzuki, Y.; Ito, O.; Mukai, N.; Takahashi, H.; Takamatsu, K. High level of skeletal muscle carnosine contributes to the latter half of exercise performance during 30-s maximal cycle ergometer sprinting. Jpn. J. Physiol. 2002, 52, 199-205. [CrossRef]

40. Aristoy, M.C.; Toldrá, F. Histidine dipeptides HPLC-based test for the detection of mammalian origin proteins in feeds for ruminants. Meat Sci. 2004, 67, 211-217. [CrossRef]

41. Mora, L.; Sentandreu, M.Á.; Toldrá, F. Contents of creatine, creatinine and carnosine in porcine muscles of different metabolic types. Meat Sci. 2008, 79, 709-715. [CrossRef]

42. Ma, D.; Kim, Y.H.B.; Cooper, B.; Oh, J.H.; Chun, H.; Choe, J.H.; Schoonmaker, J.P.; Ajuwon, K.; Min, B. Metabolomics Profiling to Determine the Effect of Postmortem Aging on Color and Lipid Oxidative Stabilities of Different Bovine Muscles. J. Agric. Food Chem. 2017, 65, 6708-6716. [CrossRef]

43. Odessey, R.; Khairallah, E.A.; Goldbert, A.L. Origin and possible significance of alanine production by skeletal muscle. J. Biol. Chem. 1974, 249, 7623-7629. [PubMed]

44. Goldstein, L.; Newsholme, E.A. The formation of alanine from amino acids in diaphragm muscle of the rat. Biochem. J. 1976, 154, 555-558. [CrossRef] [PubMed]

45. Boldyrev, A.; Abe, H. Metabolic transformation of neuropeptide carnosine modifies its biological activity. Cell. Mol. Neurobiol. 1999, 19, 163-175. [CrossRef] [PubMed]

46. Watanabe, A.; Tsuneishi, E.; Takimoto, Y. Analysis of ATP and Its Breakdown Products in Beef by Reversed-Phase HPLC. J. Food Sci. 1989, 54, 1169-1172. [CrossRef]

47. Dannert, R.D.; Pearson, A.M. Concentration of Inosine 5'-Monophosphate in Meat. J. Food Sci. 1967, 32, 49-52. [CrossRef]

48. Koutsidis, G.; Elmore, J.S.; Oruna-Concha, M.J.; Campo, M.M.; Wood, J.D.; Mottram, D.S. Water-soluble precursors of beef flavour. Part II: Effect of post-mortem conditioning. Meat Sci. 2008, 79, 270-277. [CrossRef]

49. Djenane, D.; Martínez, L.; Sánchez-Escalante, A.; Beltrán, J.A.; Roncalés, P. Antioxidant effect of carnosine and carnitine in fresh beef steaks stored under modified atmosphere. Food Chem. 2004, 85, 453-459. [CrossRef]

50. Purchas, R.W.; Rutherfurd, S.M.; Pearce, P.D.; Vather, R.; Wilkinson, B.H.P. Concentrations in beef and lamb of taurine, carnosine, coenzyme Q 10, and creatine. Meat Sci. 2004, 66, 629-637. [CrossRef]

51. Williams, P. Nutritional composition of red meat. Nutr. Diet. 2007, 64, S113-S119. [CrossRef]

(C) 2020 by the authors. Licensee MDPI, Basel, Switzerland. This article is an open access article distributed under the terms and conditions of the Creative Commons Attribution (CC BY) license (http://creativecommons.org/licenses/by/4.0/). 